\title{
THE PATHOLOGY AND CHEMISTRY OF A CASE OF GARGOYLISM
}

\author{
BY \\ R. L. BISHTON, R. M. NORMAN, AND A. TINGEY \\ From the Pathology Department, University of Bristol, and the Burden Mental Research Department, \\ Frenchay Hospital, Bristol
}

(RECEIVED FOR PUblication AUgUSt 17, 1955)

The clinical features of gargoylism are well known, but there are great gaps in our knowledge of its chemistry and pathogenesis. The condition is familial, and because of the widespread lesions in which there is an abnormal deposit it is generally thought to be a metabolic disorder. The precise nature of the material found within the cells, whether lipoid, carbohydrate, or mixtures of both, is not yet established. The present-day conception of the disease has, in fact, been built up from numerous partially examined cases. A review of the literature on gargoylism shows that histochemical studies of necropsy material have not yielded consistent results. When therefore a case of gargoylism was necropsied only five hours after death, we took the opportunity of investigating the chemistry of the liver and brain with special ref $\epsilon \mathrm{r}$ ence to their polysaccharide content.

\section{Case History}

A girl was diagnosed as a classical case of gargoylism when a large umbilical hernia was repaired at the age of 2 years. She had suffered from a nasal discharge since birth and the nasal bridge was obviously depressed. On reaching school age she was seen by a psychiatrist and found to be mentally retarded. At this time it was noted that there was clouding of the cornea, a typical gargoyle facies, an enlarged liver, and a lumbar kyphosis. At the age of 6 years a "cold" did not clear up and was followed three weeks later by increasing dyspnoea with periods of cyanosis. On admission to hospital she was placed in an oxygen tent and given penicillin but died within a few hours from the lung infection. Radiographs taken during life showed many of the stigmata of gargoylism, including the characteristic hook-shaped body of the first lumbar vertebra. She was the first child of healthy young parents with no consanguinity, and a younger sister, aged 2 years, is apparently normal and healthy.

\section{Necropsy Findings}

The post-mortem examination was made five hours after death. The body was that of a young female child showing a depressed bridge of the nose, prominent supra-orbital ridges, enlarged lobes of the ears, and a protruding tongue (Fig. 1). The hands were short and broad. The abdomen was moderately enlarged and there was an old transverse umbilical scar.

The serous cavities were healthy. The heart (150 g.) showed no abnormalities except for slight thickening of the edges of the mitral and tricuspid valve cusps. The coronary arteries did not look thickened. The aorta and main blood vessels were normal. The tongue was uniformly enlarged and its surface normal. The teeth were small and overspaced with a hyperplastic gingivitis. Both tonsils were enlarged but not inflamed. The larynx and trachea were normal. There was an acute bronchitis and bronchiolitis with mucopurulent exudate. The lungs (left 125 g., right 150 g.) showed large patches of collapse but no actual bronchopneumonic consolidation. The spleen (125 g.) was slightly enlarged, rather pale and soft. The liver was grossly enlarged $(1,090$ g.) and its cut surface had a parboiled appearance. The mesenteric lymph nodes were swollen and fleshy, but no abnormal markings were seen on bisection. The gall-bladder, bile-ducts, and pancreas appeared to be normal and there were no visible lesions in

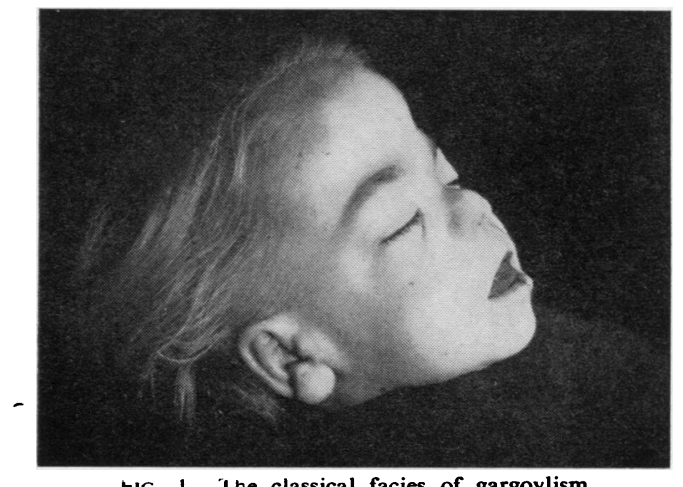

rIG. 1.- The classical facies of gargoylism. 
the alimentary tract. The kidneys (left $65 \mathrm{~g}$., right 70 g.) were of normal size and architecture. The ureters, bladder, genitals, and endocrine glands showed no macroscopic lesions. The spine showed a kyphosis with a lateral deflection towards the left side at the level of a wedge-shaped first lumbar vertebra. The skull, which appeared large, had a small coronal waist just behind the coronal suture and it was not obviously thinned. The brain $(1,405$ g.) was enlarged ; the dura mater and venous sinuses appeared normal, but the leptomeninges were opaque over the convexity and showed patches of recent haemorrhage in the right frontal region. The convolutional pattern was normal, but the sulci were rather shallow and widened; on coronal section the lateral and third ventricles were seen to be slightly dilated. The pituitary was of normal size and was removed with ease from the sella turcica, which was somewhat enlarged.

\section{Histology}

Frozen and paraffin sections were made from formol-fixed material and paraffin sections from material fixed in absolute alcohol. Blocks from

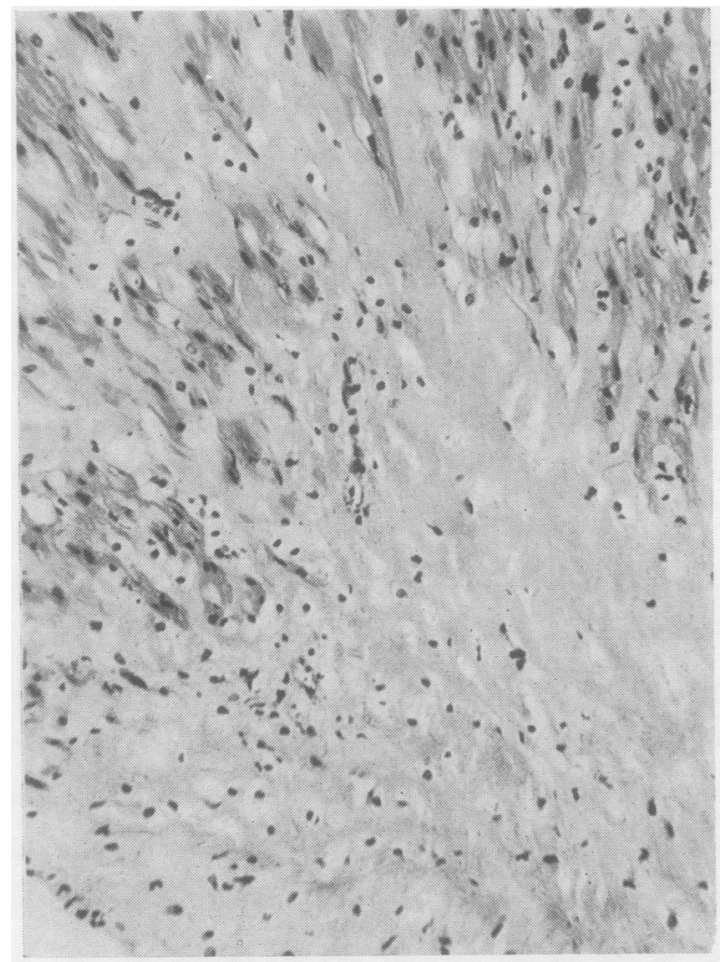

FIG. 2.-Chorda tendinea of the mitral valve; large vacuelated cells infiltrating collagenous fibrous tissue. Paraffin section. Haematoxylin and eosin. $\times 165$.

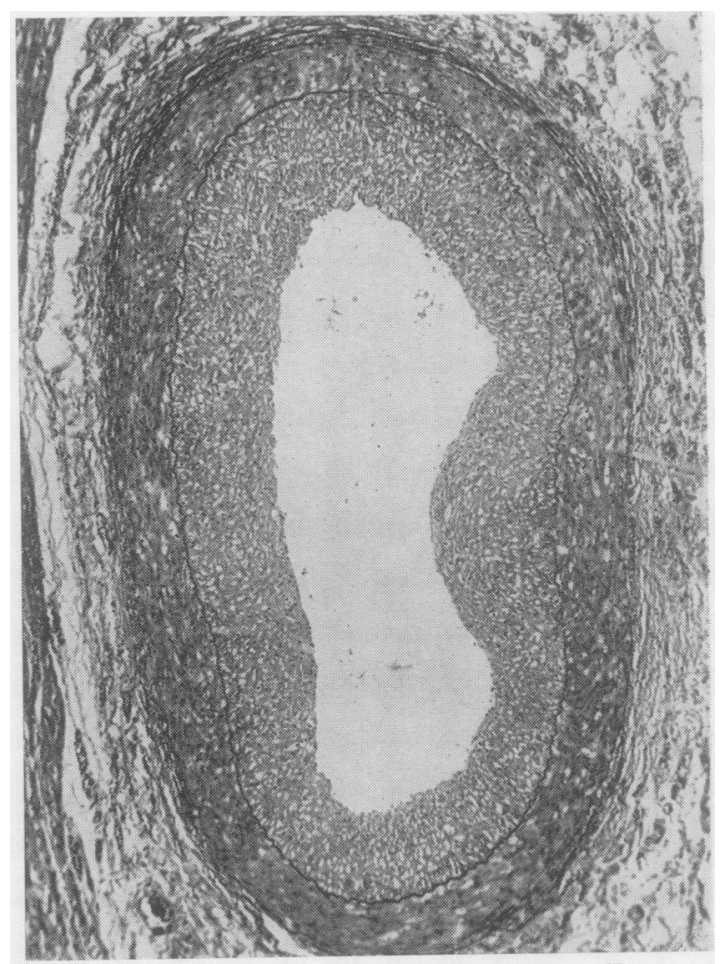

FIG. 3.-Coronary artery showing intimal thickening and numerous vacuolated cells. Paraffin section. Elastic trichrome. $\times 54$.

the brain were fixed in formol alcohol and formol bromide. Haematoxylin and eosin were the routine stains for tissues outside the central nervous system.

Heart. - The pericardium and myocardium appeared normal. The mitral valve showed an increased amount of collagenous fibrous tissue in which were many large vacuolated cells with small irregularly placed nuclei; the associated chordae tendineae were also involved (Fig. 2). The surface coronary arteries which were sectioned all showed concentric thickening of the intima (Fig. 3) by collagenous tissue in which were numerous large vacuolated cells; the media was infiltrated by a few scattered cells similar to those in the intima. There was no intimal change in the small deep branches of the coronary arteries, but the perivascular connective tissue of some of them contained a few vacuolated cells. The aorta showed no change in a section taken from the thoracic portion.

Liver.-Almost all of the parenchymal cells contained large vacuoles (Fig. 4) and the first impression was that the spaces were fat, but approprately stained frozen sections showed only a few scattered 


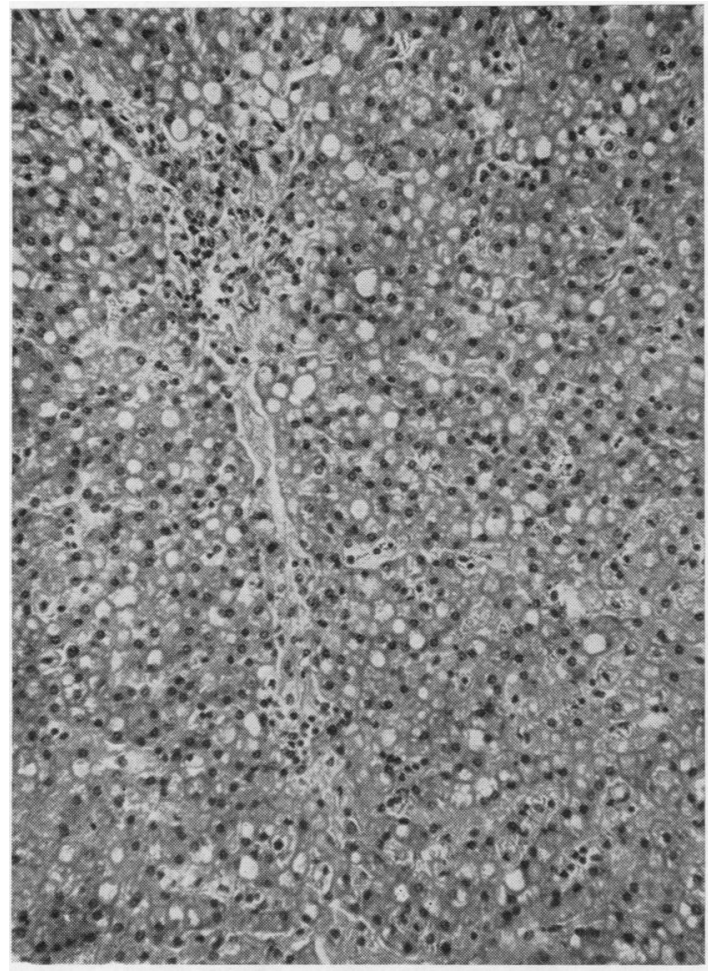

FIG. 4.-Liver: vacuolation of liver cells. Paraffin section. Haematoxylin and eosin. $\times 165$.

tiny globules of fat. The portal tracts were normal and there was no increase in fibrous tissue. Glycogen stains were negative.

Spleen.-The Malpighian bodies were widely separated, but only a few large racuolated cells could be found in the sinuses.

Mesenteric Lymph Node.-This was a striking contrast to the spleen because the sinusoids were widened and lined by numerous large vacuolated cells (Fig. 5); the lymphoid fo'licles were small and few.

Tonsil.-The lymphoid tissue appeared to be hyperplastic secondary to chronic sepsis and no vacuolated cells were seen.

Kidney.-Very careful search for vacuoles failed to reveal any in the glomeruli, tubules, blood vessels, and connective tissue; the organ appeared to be perfectly healthy.

Pituitary Gland.-There was obvious vacuolation of the chromophobes in the anterior lobe, but otherwise the gland appeared normal.

Adrenal.-The only lesion here was large groups of vacuolated medullary cells.
Skin, Tongue, Stomach, Pancreas, and Ovary.Occasional isolated large vacuoles were seen in sections of these tissues, but we were not confident in considering them abnormal.

Bone.-In the ribs and vertebral bodies the striking change was found in the periosteum. This was thickened and contained numerous large vacuolated cells (Fig. 6). The formation of bone from cartilage was abnormal in that there was no arrangement of cartilage columns at the growth line ; internally, however, the bony trabeculae appeared normal and the marrow showed no vacuolated cells.

Eye.-The left eye was examined histologically. There was a calcified cataract and a vascularized cornea. The corneal epithelium was normal and no abnormal cells were seen in the thin layer of fibrous tissue beneath it or in the adjoining capillary layer.

In all of the above tissues staining by periodic acid-Schiff methods, performic acid-Schiff methods, Nile-blue sulphate, Best's carmine stain, Congo red, Sudan black B, and Sudan IV gave negative results; the material in the vacuo'ated cells had

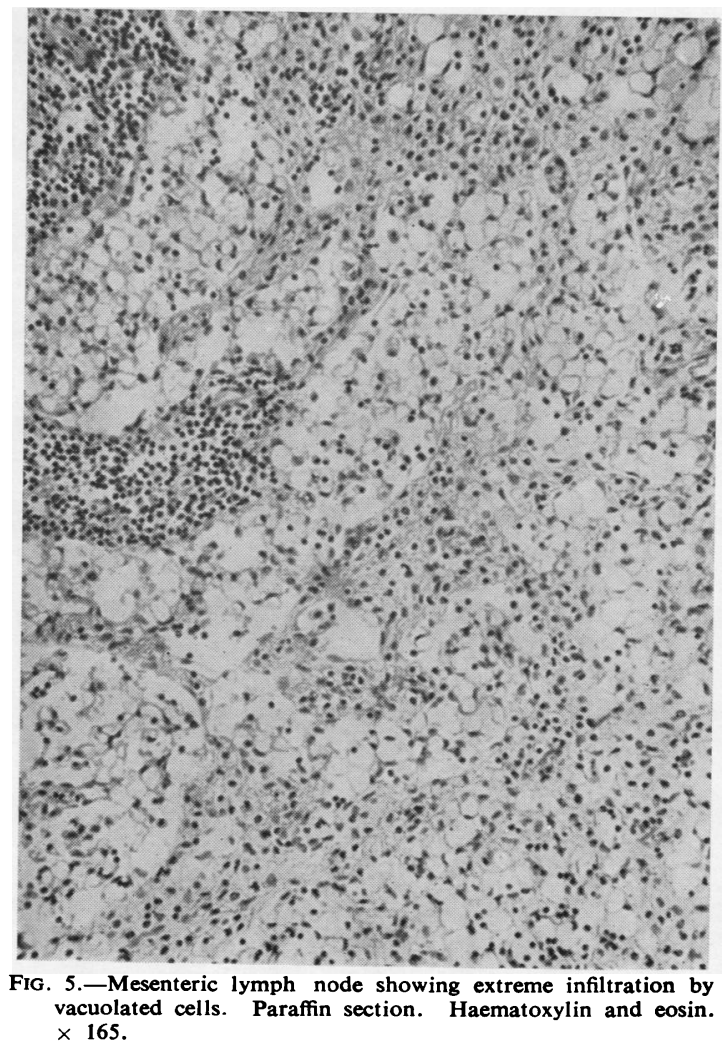




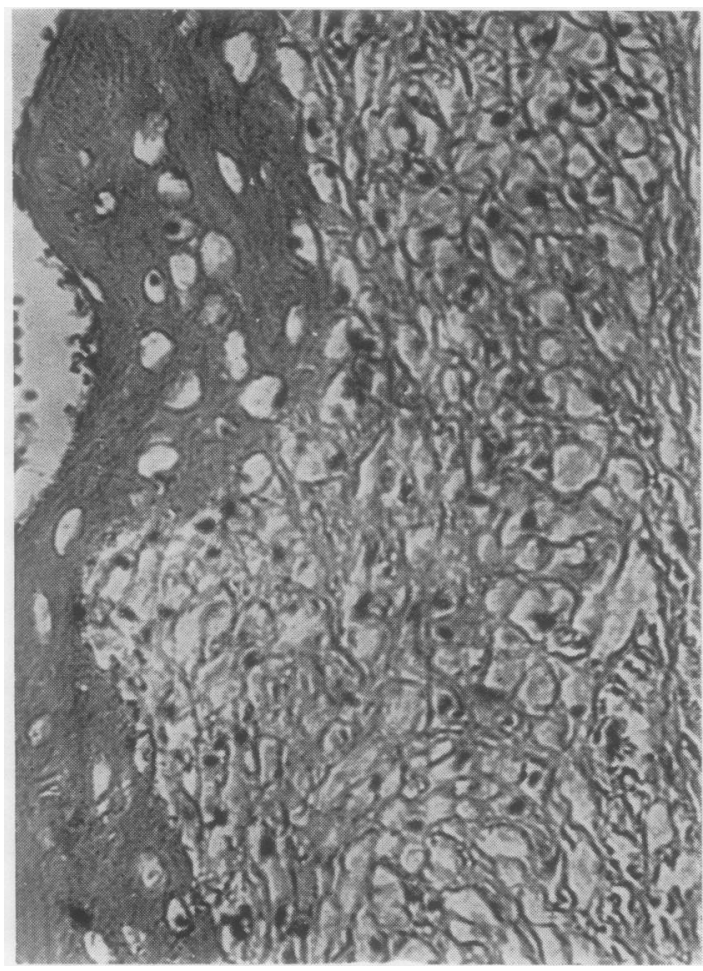

Fio. 6

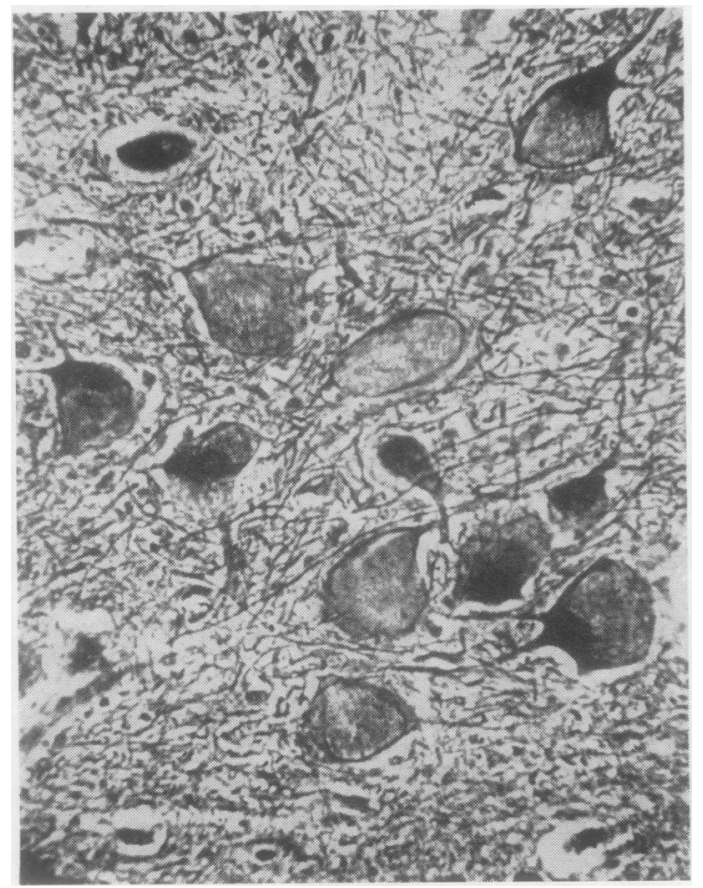

Fio. 8

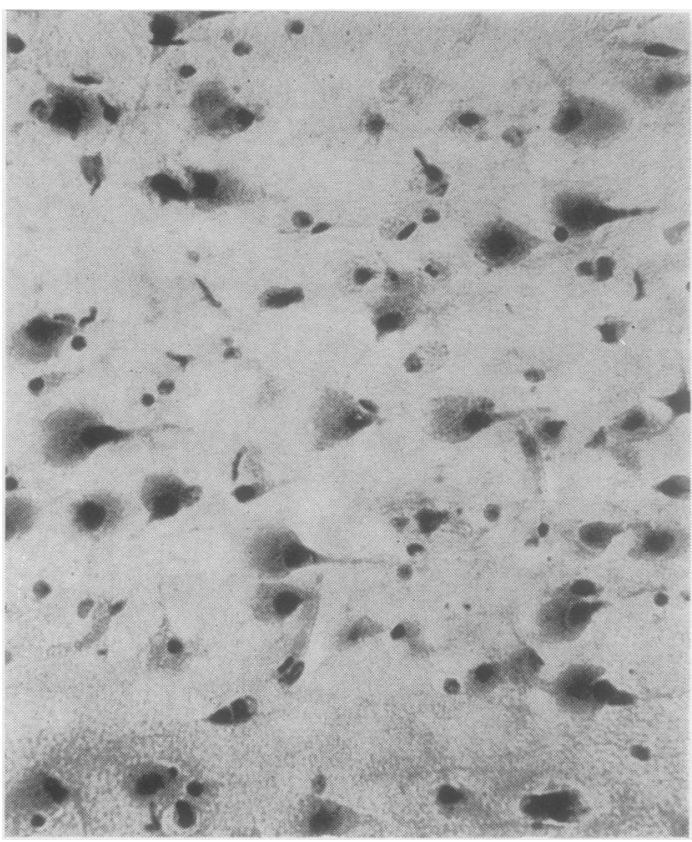

Fig. 7

FIG. 6. Periosteum of vertebra showing vacuolated cells. Paraffin o 응 section. Haematoxylin and eosin. $\times 240$.

FiG. 7.-Nerve cells of the third layer of the temporal cortex showing distension with a granular material. Carbol-azure. $\times 240$.

FiG. 8.-Nerve cells of the hypoglossal nucleus showing displacement of neurofibrils to the periphery of the cell body. Bielschowsky's method. $\times 170$.

Fig. 9.-Perivascular gliosis in the occipital grey matter. Cajal's gold sublimate method. $\times 240$.

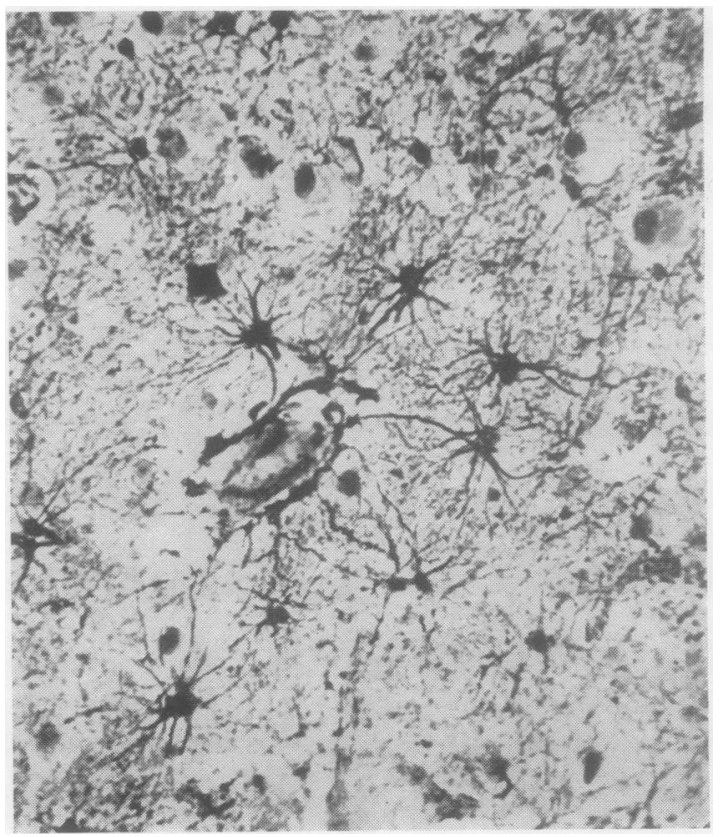

Fig. 9 
evidently been removed by solution in both the formol and absolute alcohol fixatives.

Brain.-Celloidin and frozen sections were prepared from representative areas of the cerebral cortex, basal ganglia, cerebellum, and brain-stem. They were stained by standard methods for nerve cells, axis cylinders, myelin, neuroglia, and lipoid.

Leptomeninges.-These showed fibrous thickening about $1 \mathrm{~mm}$. deep in the fronto-parietal region. No macrophage cells were seen.

Cerebral Cortex. - Here the most striking feature was the swelling of most of the large neurons. These had become spherical or pearshaped and the Nissl substance had disappeared leaving a fine granularity or reticulation in the distended cytoplasm (Fig. 7). The nuclei had been pushed to the margin of the cell, usually towards the base of the apical dendrite. The neurofibrils had also been displaced to the periphery where in larger nerve cells they formed a thin marginal rind (Fig. 8). These cells contained abnormal granules which stained a bright orange with Jackson's acetic-carbol Sudan III. The substance was not birefringent. This accumulation of granular material, though most obvious in the larger neurons of the third and fifth layers, was virtually ubiquitous. The impression gained by a study of large celloidin sections was that the occipital lobe was the least affected region. Most of the large cells of Meynert of the calcarine cortex were, however, unaltered. The giant Betz cells of the precentral gyrus, on the other hand, showed a very variable degree of involvement which ranged from the inclusion of a few granules to almost complete filling of the cell body. The small nerve cells of the fourth cortical layer and also those of the fascia dentata were only slightly swollen.

The myelination of the grey matter was generally poor, the radial bundles being sparse and the stria of Gennari and other tangential fibre systems poorly defined even in frozen sections.

The astrocytes of the molecular layer were increased in numbers and numerous small perivascular aggregations of fibrous astrocytes were present throughout the grey matter (Fig. 9). The cell bodies of the macroglia did not contain any of the granular substance found in the nerve cells and the microglia was inactive; there was no increase in oligodendroglial satellites.

Subcortical White Matter.-The central cores of the gyri and the centum semiovale were well myelinated and there was no evidence of recent breakdown of myelin; nevertheless, a generalized fibrillary gliosis was revealed in the Holzer pre-

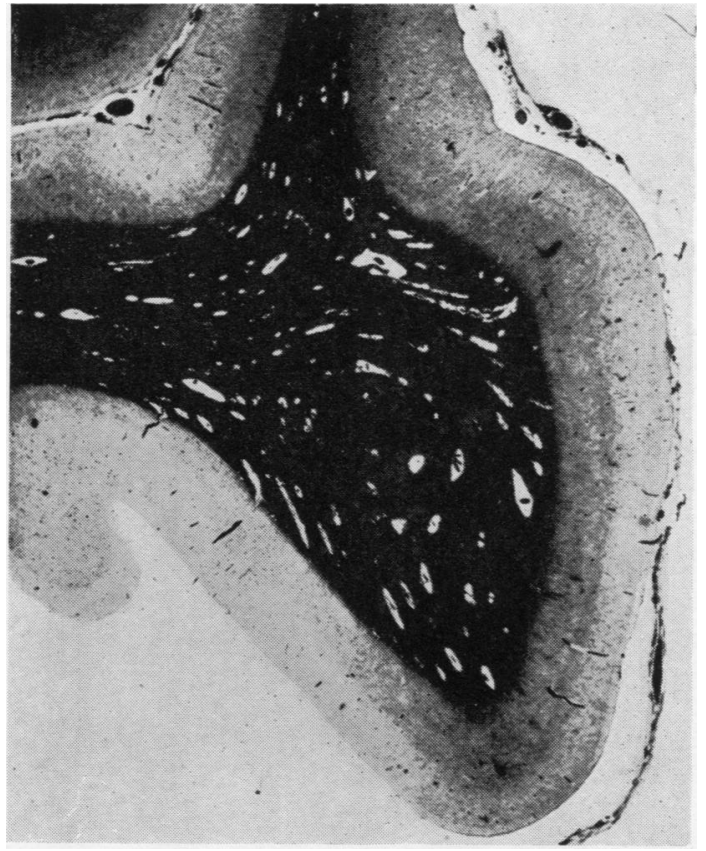

Fig. 10.-A gyrus showing numerous perivascular lacunae in th central white core. Heidenhain's myelin method. $\times 5$.

parations. The perivascular spaces in the white matter were often greatly enlarged (Fig. 10) and filled with a cellular reticulum composed mainly of collagen fibres continuous with the adventitial sheath of the vessel. There was also an admixture of astrocytes and their fibrils. Here and there the perivascular lacunae contained aggregations of compound granular corpuscles (Fig. 11) and these cells were also seen around vessels with no obvious enlargement of the perivascular space. These microglial phagocytes contained neutral fat and a few doubly refractile particles but never the relatively insoluble substance of the nerve cells (vide infra). The marginal white matter was not demyelinated, nor was there any intensification of gliosis except for what might be accounted for by shrinkage during processing.

Basal Ganglia.-The nerve cells of the thalami contained large amounts of the abnormal granular material, and in both dorso-medial nuclei there were extensive areas from which the nerve cells had disappeared and in which a heavy fibrillary gliosis was present. The myelinated fibres in these areas were reduced in number and often showed pale-staining fusiform beadings while compound granular corpuscles containing neutral fat ringed many of the neighbouring vessels. In the globus pallidus of each side the nerve cells contained 


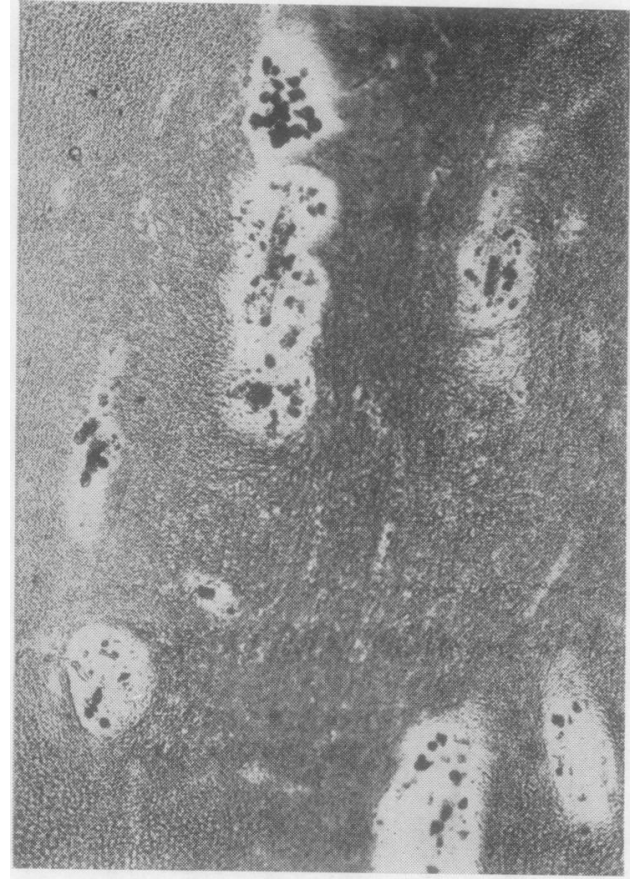

Fis. 11.-Perivascular lacunae in the occipital white matter showing groups of fat granule cells. Scharlach $R$ and haematoxylin. $\times 60$.

a variable amount of the granular lipoid substance ; myelination, however, was normal and there was no gliosis.

In the putamina and caudate nuclei conspicuous differences were seen between the degree of involvement of the large and small nerve cells, the former being greatly swollen and stuffed with lipoid while the latter were only slightly enlarged (Fig. 12). The claustra showed only minimal changes while the amygdaloid and nucleus basalis were grossly affected.

Midbrain, Pons, and Medulla.-Similar discrepancies in regional involvement were seen in these areas. In general the large motor neurons were severely affected, those of the substantia nigra, the motor nucleus of the fifth cranial nerve and the hypoglossal nucleus being greatly distended with lipoid granules, while the red nucleus, nuclei pontis, and inferior olivary cells showed little or no abnormality. The pyramidal tracts were normally myelinated but somewhat smaller in cross-section than those of a normal child of 6 years of age.

Cerebellum.-There was no apparent loss of Purkinje cells, and although virtually all contained lipoid few were conspicuously enlarged. Large oval lipoid-laden swellings of the Purkinje dendrites were commonly seen in the molecular layer

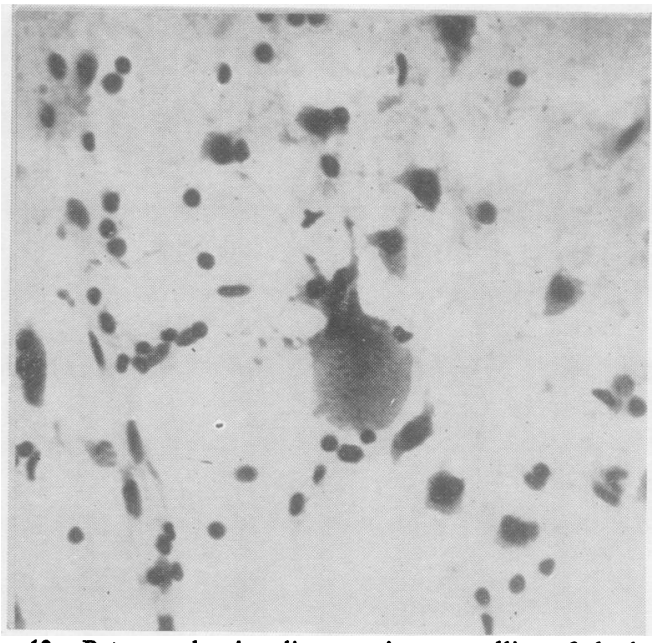

FIG. 12.-Putamen showing disproportionate swelling of the large nerve cells compared with that of the smaller ones. Carbolazure. $\times 320$.

of the vermis and less frequently in the cerebellar hemispheres (Fig. 13). No axonal torpedoes were present in the granular layer. The nerve cells of the granular layer appeared unchanged and those of the dentate nuclei were only minimally affected. Myelination of the cerebellum was within normal limits, but the whole of the white matter, as in the cerebral hemispheres, was moderately gliosed and showed a localized intensification in the hila and

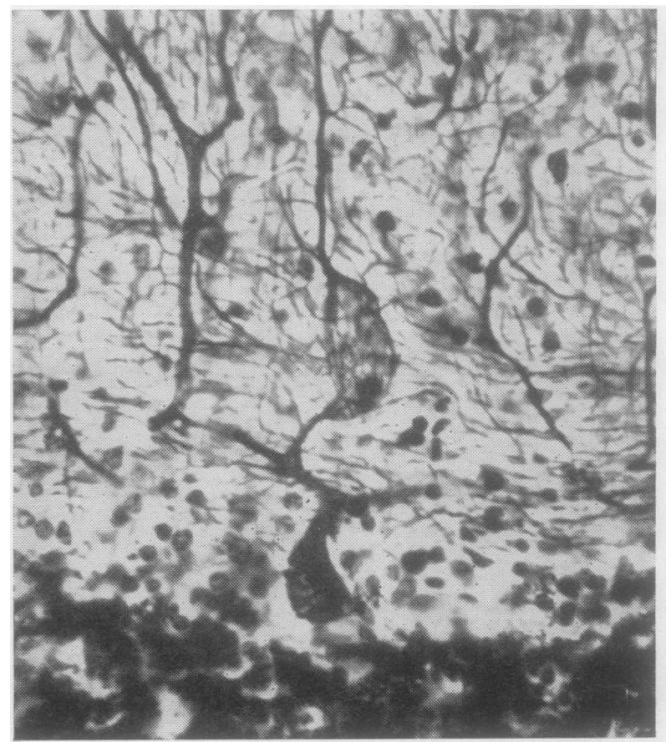

FIG. 13.-Purkinje cell showing large ovoid expansion of a dendrite. Cajal's silver nitrate-alcohol-pyridine method for the cerebellum. $\times 320$. 
periphery of the dentate nuclei. In the molecular layer a mild overgrowth of the fibrils of the Bergmann glia had taken place.

Choroid Plexus.-The epithelial cells of the choroid plexus contained lipoid granules in finely dispersed form.

Staining Reactions of Intracellular Lipoid Deposit in the Brain.-The deposit stained pale yellow with Scharlach $R$, bright orange with Jackson's acetic-carbol Sudan III, blue with Nile blue sulphate, grey with Sudan black B, and pink with Feyrter's thionin. The periodic-acid-Schiff method was strongly positive, the reaction being prevented by acetylation and restored by potassium hydroxide. A greyish-black colour was produced by the Kultschitsky-Pal stain after six days' mordanting and also by the Heidenhain myelin stain on ordinary celloidin sections. The granules did not colour with mucicarmine or with Best's stain for glycogen.

Solubility was tested by immersing frozen sections in a variety of solvents at a temperature of $60^{\circ} \mathrm{C}$. for periods up to a week's duration. The staining by P.A.S. and Feyrter's methods was negative after sections had been exposed to strong lipoid solvents (chloroform, pyridine, chloroformmethanol) for 18 hours at $60^{\circ} \mathrm{C}$. ; acetone or ether alone did not have this effect. However, after treatment with these strong solvents the granular deposits in the nerve cells still gave a bright orange colour with Jackson's Sudan III. The same results were obtained after thin blocks of tissue had been boiled in a chloroform-methanol mixture for 12 hours in a Soxhlet apparatus and then embedded in paraffin.

\section{Chemistry}

Liver.-The polysaccharide content of the gargoyle liver was compared with that of a healthy girl aged 8 years who had died from an accident and was necropsied six hours after death. A large excess of polysaccharide was present in the gargoyle liver and a series of highly complex mucopolysaccharides was isolated, the most significant one being a heparin-like polysaccharide (see Appendix).

\section{TABLE I}

DIFFERENTIAL LIPOID ANALYSIS OF THE LIVER (\% OF WET TISSUE)

\begin{tabular}{|c|c|c|c|c|c|}
\hline & & & & Gargoyle & $\begin{array}{c}\text { Normal } \\
\text { Adult }\end{array}$ \\
\hline $\begin{array}{l}\text { Total phosphatides } \\
\text { Sphingomyelin } \\
\text { Lecithin } \\
\text { Cephalin } \\
\text { Total cholesterol . } \\
\text { Cerebrosides }\end{array}$ & $\begin{array}{l}\cdots \\
\cdots \\
\cdots \\
\cdots\end{array}$ & $\begin{array}{l}\cdots \\
\cdots \\
\cdots \\
\cdots\end{array}$ & $\begin{array}{l}\ldots \\
\cdots \\
\cdots \\
\cdots \\
\ldots\end{array}$ & $\begin{array}{l}0.68 \\
{ }^{0.07} \\
0.34 \\
0.14 \\
0.27 \\
0.18\end{array}$ & $\begin{array}{ll}1.42 & 0.00 \\
& 0.87 \\
0.55 \\
0.28 \\
0.20\end{array}$ \\
\hline
\end{tabular}

A lipoid analysis of the gargoyle liver (Table I) showed no increase in cerebroside as compared with the normal. There was, however, a marked decrease in the phosphatide fraction.

Brain.-The grey matter was subjected to the same process of extraction as the liver. Both the gargoyle brain and a control gave small amounts of similar neutral and acidic polysaccharide fractions and on hydrolysis these fractions produced seemingly identical components. It was not possible to carry out quantitative comparisons on the small amounts of extracted polysaccharides. The heparin-like polysaccharide in the gargoyle liver was not found in either brain.

An analysis of the lipoid content of the brain showed no increase in the cerebrosides or other components above the normal levels (Table II). The ganglioside content of the gargoyle cortex as assessed by the estimation of hexosamine was $1.64 \%$ dry basis against our control figures of $1.27 \%$ (9 months) and $1.45 \%$ (65 years). Ganglioside as assessed neuraminic acid also showed no increase.

TABLE II

DIFFERENTIAL LIPOID ANALYSIS OF THE BRAIN (\% OF DRY TISSUE)

\begin{tabular}{|c|c|c|c|c|}
\hline & & & Gargoyle & $\begin{array}{l}\text { Normal Child } \\
\text { Aged } 5 \text { Years } \\
\text { (Brante, 1949) }\end{array}$ \\
\hline $\begin{array}{l}\text { Total lipoid } \\
\text { Cholesterol .. } \\
\text { Cerebrosides } \\
\text { Phosphatides: Total } \\
\text { Lecithin . } \\
\text { Sphingomyelin . } \\
\text { Cephalin . } \\
\text { Unidentified lipoids }\end{array}$ & $\begin{array}{l}\cdots \\
\cdots \\
\cdots \\
\cdots \\
\cdots \\
\cdots \\
\cdots\end{array}$ & $\begin{array}{l}\cdots \\
\cdots \\
\cdots \\
\cdots \\
\cdots \\
\cdots\end{array}$ & $\begin{array}{rr}33.5 & \\
6.6 & \\
4 \cdot 0 & \\
18 \cdot 5 & \\
& 5 \cdot 1 \\
& 1 \cdot 8 \\
& 11 \cdot 6\end{array}$ & $\begin{array}{rr}34.6 & \\
5 \cdot 1 & \\
3 \cdot 2 & \\
20 \cdot 1 & \\
& 7 \cdot 6 \\
& 1 \cdot 4 \\
& 11 \cdot 1\end{array}$ \\
\hline
\end{tabular}

\section{Discussion}

The outstanding feature in this case of gargoylism is the complete removal of the infiltrating material by formalin and by alcohol fixat:on from all tissues excepting the brain. The material must be very soluble in these fixatives; its disappearance cannot be accounted for by post-mortem autolysis because chemical extraction showed a threefold increase in the amount of polysaccharides in the liver. The polysaccharides extracted from the liver were insoluble in $95 \%$ ethanol, and it seems therefore that the material which dissolved out during fixation must have been a soluble polysaccharide complex.

Strauss (1948), Dawson (1954), and others have failed to stain the liver infiltrate in post-mortem material. Nisbet and Cupit (1954), on the other hand, were able to stain most of the liver infiltrate in alcohol-fixed material. Best's carmine stain showed much red-staining material, but it did not 
account for the whole of the infiltrate. Much more material stained positively with the periodicacid-Schiff method, and they suggested that the liver infiltrate consists of at least two abnormal substances of carbohydrate nature.

Lindsay, Reilly, Gotham, and Skahen (1948), although unable to stain post-mortem material, were able to stain the infiltrate in fresh biopsy material. In one case the infiltrate in cartilage stained with Best's carmine stain and in another case positive staining of liver and cartilage biopsies was obtained by the Feulgen-Bauer method. Henderson, Macgregor, Thannhauser, and Holden (1952), however, failed to stain the abnormal deposit in liver biopsy material from two cases of gargoylism.

In spite of the great difficulty in staining the infiltrate outside the nervous system it appears that those who have had partial success with either biopsy or post-mortem material believe it to be a carbohydrate. Their opinions, based on histochemical findings, are confirmed by the results of our chemical extraction of the liver. Furthermore, the chemical studies show that the liver disorder is not simply the deposition of a particular carbohydrate but that normal glycogen storage is replaced by an accumulation of many complex polysaccharides. It is therefore not surprising that the histochemical results obtained with different stains should be variable. We believe it is to be expected that mucopolysaccharides like the "heparin-type" isolated from the liver may show little or no reaction to periodate. The reaction of complex polysaccharides with the periodic-acid-Schiff staining technique is smaller than that of simple polysaccharides because groups such as sulphate and $\mathrm{N}$-acetamide prevent the periodate attack. Thus, heparin shows only $25 \%$ of the reaction of glycogen. With our " heparin-type" polysaccharide, which we know contains sulphate and substituted amino groups, the reaction will be certainly much less than glycogen and it is quite conceivable that it would not react at all, especially if it is involved in complex formation in the tissue itself. It would be perhaps best to use dyes such as toluidine blue for staining " heparin-type" polysaccharides, sinc? it is known that these are strongly absorbed on such polysaccharides.

The widespread lesions of gargoylism are listed by Henderson et al. (1952), and their excellent review of the literature shows that there is much variation in the distribution and severity of the lesions, although the brain, liver, and spleen are invariably affected. In our case the striking differences in involvement of the spleen, tonsil, and lymph node exemplify the capricious and inexplicable distribution of the infiltrate.

The thickening of the leptomeninges in gargoylism has had little attention though there have been occasional references to the opacity of the piaarachnoid on naked-eye examination. Where marked fibrosis has been found, as in the cases of Green (1948), Russell (1949, Magee (1950), and Dawson (1954), internal hydrocephalus has also been present. In this case the thickening was much greater over the convexity than at the base, and the lateral ventricles were only slightly dilated. Russell has suggested that the meningeal fibrosis in gargoylism follows a low-grade inflammatory reaction set up by lipoid deposition and that the hydrocephalus is the result of partial obstruction to the subarachnoid space. In her case granular material similar in staining properties to that of the neurons was found in the arachnoid cells. Tuthill (1934) recorded similar swelling of the connective tissue cells and the presence of conglomerate masses of lipoid particles in the thickened meninges. The collagenous proliferation of the pia-arachnoid described by Magee reached the extraordinary depth of half a centimetre and completely obscured the convolutional pattern of theo underlying brain. In his case the numerous macrophages enmeshed in the fibrous tissue coneo tained both neutral fat and an unidentified material which coloured poorly or not at all with lipoid stains. In Magee's opinion the meningeal changes represented an extension of the generalized abnormalities of connective tissue found elsewhere in the body. The meninges in Green's (1948) case were also thickened and contained scattered compound granular corpuscles and macrophages ; but Strauss, who had reported on the general pathology, attributed the hydrocephalus to a bony deformity of the base of the skull and cited other examples of gargoylism showing this feature. In one of these, $\mathrm{Nja}$ 's (1946) case, the chief bony protuberance was of the orbital plates, and it is not easy to understand how dilatation of the ventricles could be attributed to this factor alone. There can be little doubt that partial obstruction of the subarachnoid space by fibrosis remains the most likely cause of the hydrocephalus as distinct from the abnormal contour of the head. In our case the large brain was evidently not the direct consequence of hydrocephalus.

The pathological alterations of the nerve cells caused by the storage in the cytons of an abnormal granular substance did not differ materially from what has been described by others. There was the same severe, almost ubiquitous, but by no 
means uniform, involvement of the cerebral cortex. The literature contains many references to reduction in the number of nerve cells of the cortex and other regions, but in our case the only certain instance of this was seen in the areas of substantial neuronal loss in the medial thalamic nuclei. There were striking local variations in the degree of affection of certain cell groups. In the corpus striatum the gross distension of the large nerve cells of the putamen and caudate nucleus was in marked contrast to the minimal swelling of the smaller elements. Similarly, in the brain-stem the larger motor neurons were often greatly altered while the inferior olives and nucleus pontis appeared almost normal. Until more detailed records are available one cannot say whether such regional variations are mere individual peculiarities or are characteristic of the disease process itself.

In the cerebellum we were able to confirm Jervis's (1950) and Dawson's findings of large ovoid expansions of the dendrites of the Purkinje cells. These swellings were filled with granules similar to those of the nerve cell bodies. In this, as in other respects, there is a close resemblance to the lesions seen in the amaurotic family idiocy group, although the especially severe atrophy of the granular layer of the cerebellum sometimes found in the juvenile type has yet to be reported in a gargoyle.

The enlarged, almost cyst-like, perivascular spaces seen in the cerebral white matter are one of the lesser-known pathological findings in gargoylism. They were first reported by Tuthill, who regarded them as the consequence of adventitial hypertrophy, and they have recently been the subject of special consideration by Naidoo (1953). Perivascular cyst formation has also been described by Scheinker (1947) in the white matter of epileptic brains and was attributed by him to tissue breakdown following functional circulatory disturbances. Perhaps the similarly dilated perivascular spaces recently reported by Crome (1954) in a case of tuberose sclerosis originated in this way. However, epilepsy is almost unknown in gargoylism, and in our case there was no perivascular gliosis or demyelination. Moreover, no space contained more than a few cells containing fat granules whereas in many there was a marked collagenous overgrowth. Tuthill's theory of adventitial hypertrophy therefore seems plausible and has the further advantage of linking the perivascular changes with the fibrosis of the leptomeninges.

The histochemical findings in our case correspond well with what Dawson reported; the nerve cells contained a P.A.S.-positive substance extract- able by the more powerful lipoid solvents. It cannot, however, be maintained that these histochemical findings are peculiar to the gargoyle brain, since we have obtained identical results with the brains of two juvenile amaurotic idiots. Furthermore, since the total cerebroside and ganglioside content of the gargoyle brain was not significantly raised, the abnormality of lipoid metabolism must presumably be one of redistribution of the lipoid fractions rather than a simple excess storage in this case.

Dawson suggested that the primary disturbance in gargoylism is one of polysaccharide or mucopolysaccharide metabolism and that in the nervous system polysaccharides and the phosphatides or cerebrosides combine, producing compounds of varying solubility. A distinction may certainly be drawn between the rapidly diffusible substance in the liver and the relatively insoluble material which is present in the nerve cells and resembles a cerebroside. Brante $(1951,1952)$ showed that the infiltrate in neurones had the properties of a ganglioside (gangliosides have cerebroside and polysaccharide components). In the other tissues, Brante found much diffusible material with the properties of a mucopolysaccharide.

The chemical analysis of the gargoyle liver showed a quantitative increase in mucopolysaccharides. In the gargoyle and control brains the amounts of polysaccharide complexes extracted were insufficient for an adequate quantitative assessment. However, the important point emerges that the heparin-type polysaccharide extracted from the liver was not found amongst the brain polysaccharides. It is also interesting to mention that a similar investigation of the spleen from this gargoyle showed the heparin-type polysaccharide to be definitely absent.

\section{Summary}

The pathological findings in a case of gargoylism are described with a detailed chemical investigation of the liver and brain. There was evidence that the normal glycogen in the liver was deficient and had been replaced by the accumulation of a series of highly complex mucopolysaccharides. An unusual heparin-like polysaccharide in the gargoyle liver was not found in either the brain or spleen. This polysaccharide is not likely to stain well, if at all, by the periodic-acid-Schiff technique but should stain strongly with toluidine blue. Although the nerve cells contained abnormal granules of a P.A.S.-positive substance, chemical analysis of the brain showed no significant increase in the cerebroside or ganglioside content. 
We are indebted to Professor A. V. Neale for permission to publish this case ; to Professor T. F. Hewer for criticism ; and to Mr. D. N. White for the photography.

\section{REFERENCES}

Brante, G. (1949). Acta physiol. scand., 18, Suppl. 63, Table IX. (1952). Scand. J. clin. Lab. Invest., 4, 43.

Crome, L. (1954). Arch. Dis. Childh., 29, 136.

Dawson, I. M. P. (1954). J. Path. Bact., 67, 587.

Green, M. A. (1948). J. Neuropath., 7, 399.

Henderson, J. L., Macgregor, A. R., Thannhauser, S. J., and Holden, R. (1952). Arch. Dis. Childh., 27, 230.

Jervis, G. A. (1950). Arch. Neurol. Psychiat., Chicago, 63, 681.

Lindsay, S., Reilly, W. A., Gotham, T. J., and Skahen, R. (1948). Amer. J. Dis. Child., 76, 239

Magee, K. R. (1950). Arch. Neurol. Psychiat., Chicago, 63, 282.

Naidoo, D. (1953). J. ment. Sci., 99, 74.

Nisbet, N. W., and Cupit, B. F. (1954). Brit. J. Surg., 41, 404

Nja, A. (1946). Acta paediat., Uppsala, 33, 267.

Russeli, Dorothy S. (1949). Observations on the Pathology of Hydrocephalus, p. 52 . Spec. Rep. Ser. med. Res. Coun. (Lond.), No. 265.

Scheinker, I. M. (1947). Res. Publ. Ass. Res. nerv. ment. Dis., $26,35$.

Strauss, Lotte (1948). Amer. J. Path., 24, 855.

Tuthill, C. R. (1934). Arch. Neurol. Psychiat., Chicago, 32, 198.

\section{A P PENDIX}

\section{CHEMICAL ANALYSIS OF TISSUE POLYSACCHARIDES}

\author{
BY
}

\section{STACEY AND S. A. BARKER \\ From the Chemistry Department, University of Birmingham}

We have compared the polysaccharide contents of the livers of two young subjects, one with gargoylism and the other a child who had died 12 hours after an accident. In both cases the enzyme action in these tissues was arrested by freezing before glycogenolysis could have been completed, and crude polysaccharide mixtures were isolated by identical procedures involving (a) hot water extraction following prior removal of fats and colouring matter with acetone and chloroform, and (b) alkaline extraction of the residue, neutralization with glacial acetic acid, removal of the precipitate, and isolation of the crude polysaccharide in the supernatant. A solid wax was obtained from the acetone/chloroform extract of the gargoyle liver. The bulk of the protein was removed from the crude polysaccharides by chloroform/butanol treatment. The amounts of crude polysaccharides isolated from the "gargoylism" liver (approximately $7 \mathrm{~g}$. from $220 \mathrm{~g}$. of wet tissue) were surprisingly three times those from a corresponding weight of the "accident" liver.

To separate these polysaccharide mixtures a novel scheme was devised in which the key reagent employed (Jones, 1953 ; Dutta, Jones, and Stacey, 1953) was "cetavlon" (cetyltrimethylammonium bromide). This precipitates sulphated polysaccharides such as heparin, mucoitin sulphate, chondroitin sulphate, and dextran sulphate, but not " neutral" polysaccharides such as glycogen, blood group polysaccharides and dextran.

The water-extracted "gargoylism" polysaccharide (S, 3.95\%) contained a larger proportion of "cetavlon" precipitable polysaccharide (from 33-50\%) than that ( $\mathrm{ca} 20 \%$ ) of the corresponding " accident" polysaccharide (S, $0.57 \%)$. Both " cetavlon "-precipitated fractions showed strong infra-red absorption at 1,230$55 \mathrm{~cm}^{-1}$ indicating that they were sulphated, but their spectra in the region $720-1,000 \mathrm{~cm}^{-1}$ were very different. The gargoylism fraction, whose infra-red spectrum showed most but not all the features of that of heparin, was refractionated with "cetavlon," the precipitated fraction (S, 7.68\%) having $[\alpha]_{\mathrm{D}}^{17}+18.1^{\circ}$ (water) and the soluble fraction (S, 6.26\%) $[\alpha]_{D}^{17}+37.2^{\circ}$ (water). Although both these latter fractions when hydrolysed showed, after ionophoresis in borate buffer $p \mathrm{H} \mathrm{10}$, a component inter alia whose $\mathrm{Mg}$ value and colour with aniline hydrogen phthalate were identical with the main hydrolysis product (believed to be the heparosin-sulphuric acid of Wolfrom, Montgomery, Karabinos, and Rathgeb, 1950) of heparin, they showed only a slight but definite blood anticoagulant activity (" cetavlon "-precipitated fraction, $1.1 \%$, and "cetavlon" soluble, $0.56 \%$, of the activity of international standard heparin).

The "neutral" polysaccharides which were not precipitated by the "cetavlon" treatment of the waterextracted liver polysaccharides could be further fractionated using $85 \%$ acetic acid, any glycogen present being precipitated under these conditions. Pure glycogen (which had $[\alpha]_{\mathrm{D}}^{20}+197^{\circ}$; stained red with iodine, was attacked by glucamylase, $\beta$-amylase, and $\alpha$-amylase, gave only glucose after acid hydrolysis ; was free from sulphate and contained no $N$-acetyl or carboxylic acid groups) could be isolated in an overall yield of $8.3 \%$ of the crude water-extracted " accident " polysaccharide mixture. On the other hand, less than $0.3 \%$ [ $4 \mathrm{mg}$. from $1.638 \mathrm{~g}$.] of a crude glycogen fraction (which had $[\alpha]_{\mathrm{D}}^{17}+115^{\circ}$; stained red with iodine ; was attacked by $\alpha$-amylase; gave glucose as the main component after acid hydrolysis with traces of galactose, glucuronic acid, and glucosamine ; was free from sulphate) could be obtained from the corresponding "gargoylism" liver polysaccharide. This observation was confirmed in our laboratories by Professor $\mathbf{M}$. Heidelberger, who showed that, whereas the crude water-extracted " accident" polysaccharide gave large precipitates with anti-pneumococcus sera of types II and XII, no observable reaction was obtained with the corresponding "gargoylism" liver polysaccharide. However, both the pure "accident" glycogen and the crude "gargoylism" glycogen reacted strongly with type XII anti-serum. Glycogens from many sources are known (Heidelberger, Aisenberg, Cori, Hassid, and Pacsu, 1953) to give specific precipitates in the cold with antibodies in the horse to the pneumococcal types II and XII. Serological tests also confirmed the absence of glycogen from the "cetavlon "-precipitated fractions. 
At least two other polysaccharides accompanied the trace of glycogen in the soluble fraction after " cetavlon" treatment of the water-extracted " gargoylism" polysaccharide. One of these was precipitated together with the glycogen by $85 \%$ glacial acetic acid and could be largely separated from it by alcohol fractionation, the glycogen being precipitated with one volume of ethanol and this polysaccharide, "A," with four volumes of ethanol. Polysaccharide A (overall yield, $1.4 \%)$ had $[\alpha]_{D}^{17}+58.7^{\circ}(c, 0.264$ in water) and when hydrolysed showed galactose (ca 3 parts) and glucose (ca 1 part) as its main components together with small amounts of glucosamine and glucuronic acid. Other ninhydrin-reacting components (probably amino-acids) were detected. The other polysaccharide, B (overall yield, $13.5 \%)$, had $[\alpha]_{D}^{17}+7.5^{\circ}(c, 0.47$ in water $)$, and when hydrolysed showed inter alia glucose, galactose, glucosamine, and a trace of glucuronic acid, together with amino-acids (including glutamic acid, aspartic acid). Although the crude water-extracted "gargoylism" polysaccharide showed an almost negligible reaction with anti-serum of pneumococcus type XIV, polysaccharide $A$ gave a weak reaction and polysaccharide $B$ a strong reaction. It appears therefore that polysaccharide $B$, in particular, must bear a strong resemblance to the type XIV specific polysaccharide (shown to contain glucose, galactose and glucosamine, Barker, Heidelberger, and Stacey, unpublished results) and to the blood group polysaccharides which also react with type XIV anti-serum (Kabat, Bendich,
Bezer, and Knaub, 1948). Both polysaccharides $A$ and $B$ showed infra-red absorption at 1,648 and $1,550 \mathrm{~cm} .^{-1}$ attributable to a $\mathrm{R}-\mathrm{N}-\mathrm{C}$ grouping (including $N$ -<smiles></smiles>

acetyl) and only very weak absorption at 1,235-55 $\mathrm{cm} .^{-1}$ indicating that it contained few, if any, sulphate groups.

It will be seen that a profound carbohydrate metabolic upset has taken place in the gargoyle liver knocking out the normal glycogen storage and building up a series of highly complex mucopolysaccharides. Another mixture, from which the heparin-like polysaccharide was significantly absent, has been isolated from the spleen in this case, and this is now under investigation.

The authors wish to express their thanks to Professor M. Heidelberger for performing the serological tests and to Dr. C. R. Ricketts for carrying out the anticoagulant activities.

\section{REFERENCES}

Barker, S. A., Heidelberger, M., and Stacey, M. Unpublished

results. Acta, 10, 613.

Heidelberger, M., Aisenberg, A. C., Cori, G. T., Hassid, W. Z., and Pacsu, E. (1953). Science, 117, 467.

Jones, A.S. (1953). Biochim. biophys. Acta, 10, 607.

Kabat, E. A., Bendich, A., Bezer, A. E., and Knaub, V. (1948). J. exp. Med., 87, 295.

Wolfrom, M. L., Montgomery, R., Karabinos, J. V., and Rathgeb, P. (1950). J. Amer. chem. Soc., 72, 5796. 